\title{
Differential expression of vasoactive intestinal peptide receptor 1 expression in inflammatory bowel disease
}

\author{
TOMOMI YUKAWA, NOBUHIDE OSHITANI, HIROKAZU YAMAGAMI, \\ KENJI WATANABE, KAZUHIDE HIGUCHI and TETSUO ARAKAWA

\begin{abstract}
Department of Gastroenterology, Osaka City University Graduate School of Medicine, 1-4-3 Asahi-machi, Abeno-ku, Osaka 545-8585, Japan
\end{abstract}

Received March 23, 2007; Accepted April 30, 2007

\begin{abstract}
There is conflicting evidence regarding the significance of vasoactive intestinal peptide (VIP) in inflammatory bowel disease (IBD). Involvement of the VIP receptor in IBD has not been reported. We examined the expression and localization of the VIP receptor in IBD. We determined the location of VIP receptor 1 (VIPR1) immunohistologically in surgically resected intestinal samples from 10 controls, 15 patients with ulcerative colitis, and 10 patients with Crohn's disease. A fluorescein-linked immunohistological study was performed using anti-VIPR1 antibody, with doublestaining with antibodies to CD3, CD19, and CD68. Correlations with interleukin (IL)-4 and TNF- $\alpha$ expression were also investigated. Results showed that the number of VIPR1-positive cells was significantly increased in the inflammatory mucosa. VIPR1 was expressed in CD3-, CD19-, and CD68-positive cells. The proportion of VIPR1-positive cells among CD3positive cells was significantly higher in the lamina propria of patients with ulcerative colitis than in those with Crohn's disease and the controls. The proportion of VIPR1-positive cells among CD68-positive cells was significantly higher in patients with ulcerative colitis and Crohn's disease than in the controls. A correlation between the numbers of VIPR1- and IL-4-positive cells was found in patients with ulcerative colitis, and between the numbers of VIPR1- and TNF- $\alpha$-positive cells in patients with Crohn's disease. In conclusion, VIPR1 was widely expressed in infiltrating inflammatory cells, especially CD3- and CD68-positive cells in ulcerative colitis mucosa and CD68-positive cells in Crohn's disease mucosa. The differential expression of VIPR 1 in ulcerative colitis and Crohn's disease mucosa suggests that the VIP system plays different roles in the pathogenesis of IBD.
\end{abstract}

Correspondence to: Dr Nobuhide Oshitani, Department of Gastroenterology, Osaka City University Graduate School of Medicine, 1-4-3 Asahi-machi, Abeno-ku, Osaka 545-8585, Japan

E-mail: nobu@med.osaka-cu.ac.jp

Key words: vasoactive intestinal peptide receptor 1, inflammatory bowel disease, immunohistochemistry

\section{Introduction}

Ulcerative colitis (UC) and Crohn's disease (CD) together comprise idiopathic inflammatory bowel disease (IBD) of unknown etiology. Immunological abnormalities have been implicated in the pathogenesis of IBD, and immunosuppressive therapies are effective in the treatment of IBD. Activation of humoral immunity based on T-helper type 2 (Th2)-shifted immunity has been implicated in the pathogenesis of UC, while T-helper type 1 (Th1)-shifted activation of cellular immunity plays an important role in the pathogenesis of $\mathrm{CD}$, together with abnormality of macrophages $(1,2)$. Vasoactive intestinal peptide (VIP) is a typical neuropeptide distributed in the central nervous system and intestine, and is known to have anti-inflammatory activity. Effects of VIP on the immune system have recently been described. VIP regulates the expression of co-stimulatory molecules, and may modulate the shift toward Th1 and Th2 differentiation. In the last decade, VIP has been included in the list of potential candidates for use in treating inflammatory and autoimmune disorders, such as multiple sclerosis, rheumatoid arthritis, insulin-dependent diabetes mellitus, and IBD (3-5). Kimura et al reported a decrease in the number of VIPpositive nerves in severe inflammatory lesions in active UC and CD (6). Some studies have shown that VIP shifts the Th1/Th2 cytokine balance in IBD (7). Abad et al reported that VIP reduced the clinical and histopathologic severity of trinitrobenzene sulfonic acid (TNBS)-induced colitis (8). However, the involvement of the VIP receptor in IBD has not been studied. We examined the localization of VIP receptor 1 (VIPR1) in the human intestine using immunohistological methods.

\section{Materials and methods}

Patients. Tissue specimens were obtained during surgery performed on 15 patients with UC ( 7 males, 8 females, mean age 40.9 years, range $23-70), 10$ patients with CD (7 males, 3 females, mean age 36.8 years, range $27-48$ ), and 10 patients with colon cancer (9 males, 1 female, mean age 65.5 years, range 55-80) at Osaka City University Hospital and Osaka City General Hospital. Macroscopically normal mucosa was obtained from patients who underwent surgery for colon cancer and used as control samples. All patients were 
Table I. Patients and disease activity.

\begin{tabular}{lcccc}
\hline & UC active & UC quiescent & CD & Control \\
\hline Age & $49.3 \pm 16.5$ & $31.1 \pm 7.01$ & $36.8 \pm 5.76$ & $65.5 \pm 8.51$ \\
Sex (male/female) & $3 / 5$ & $4 / 3$ & $7 / 3$ & $9 / 1$ \\
Duration of disease & $8.69 \pm 10.5$ & $8.57 \pm 4.96$ & $10.1 \pm 7.89$ & \\
Involvement & 7 & & & \\
Total colitis & 1 & 5 & \\
Left-sided colitis & $11.6 \pm 3.93$ & 2 & \\
CAI & $8.0 \pm 2.27$ & $4.0 \pm 1.29$ & \\
DAI & $22.5 \pm 25.5$ & $2.9 \pm 1.46$ & \\
Prednisolone (mg/day) & $10028 \pm 20004$ & $12.6 \pm 13.0$ & \\
Total steroid dose & & $15971 \pm 7963.7$ & \\
Location (L1/2/3) & & & $4 / 2 / 4$ & \\
Behavior (B1/2/3) & & & $246.6 \pm 64.0$ & \\
CDAI & & & \\
\hline
\end{tabular}

Japanese. The diagnosis of IBD was based on colonoscopy, histopathological examinations, and clinical features. Twelve patients with UC had total colitis, while 3 had left-sided colitis. Regarding the location of the disease, 4 patients with CD had L1, 2 had L2, and 4 had L3 disease, and regarding the behavior of the disease, 1 patient was B1, 4 were B2, and 5 were B3 according to the Montreal classification (9). Six patients with CD underwent surgery for stenosis or obstruction, 3 for perforation and fistula, and one for melena. For UC patients, the mean daily dose of prednisolone before surgery was $18.7 \mathrm{mg} /$ day $(0-60 \mathrm{mg})$. Two patients with UC received cytapheresis, and all UC patients except one were taking 5-aminosalicylic acid (5ASA) or sulfapyridine (SASP). Preoperatively, 7 patients with $\mathrm{CD}$ were treated with total parenteral nutrition, two patients were receiving corticosteroids, and 3 patients received infliximab infusion (Table I).

Clinical activity in patients. The activity index of UC was calculated as the clinical activity index (CAI) (10). We considered patients with a $\mathrm{CAI}>7$ to have an active disease.

In the 8 patients with active UC, the mean CAI at the time of surgery was $11.6(7-17)$, while in the 7 patients with quiescent $\mathrm{UC}$, the mean CAI at the time of surgery was 4 (2-6).

The disease activity of $\mathrm{CD}$ was calculated as the $\mathrm{CD}$ activity index (CDAI) (11). In CD patients, the mean CDAI at the time of surgery was 246.6 (134-338).

Immunohistochemistry. An approximately $5 \times 5-\mathrm{mm}$ segment was excised from the intestine and immediately fixed in periodate/lysine $/ 2 \%$ paraformaldehyde at $4^{\circ} \mathrm{C}$ for $6 \mathrm{~h}$, and then incubated in a $10-15-20 \%$ sucrose gradient in phosphate-buffered saline (PBS) at $4^{\circ} \mathrm{C}$ for $6 \mathrm{~h}$. Specimens were embedded in OCT compound (Miles Sankyo, Tokyo, Japan) in dry ice/acetone, and stored at $-80^{\circ} \mathrm{C}$ until use.

Cryostat sections ( $4 \mu \mathrm{m}$-thick) were cut and pretreated with $2 \%$ goat serum with PBS to inhibit non-specific protein binding. After washing, sections were first reacted with primary antibody (rabbit anti-VIPR1 antibody, VIPR1;
Table II. Antibodies.

\begin{tabular}{lllc}
\hline Antibody & \multicolumn{1}{c}{ Supplier } & Species & Working dilution \\
\hline CD3 & Dako & Mouse & $1: 200$ \\
CD19 & Dako & Mouse & $1: 200$ \\
CD68 & Dako & Mouse & $1: 500$ \\
VIPR1 & Chemicon & Rabbit & $1: 500$ \\
IL-4 & R\&D Systems & Mouse & $1: 500$ \\
TNF- $\alpha$ & Dako & Mouse & $1: 1000$ \\
\hline
\end{tabular}

Chemicon International, Temecula, CA, USA) at $4^{\circ} \mathrm{C}$ overnight (Table II). After washing three times in PBS containing $0.05 \%$ Tween-20 (PBS-T), sections were reacted with FITCconjugated goat anti-rabbit IgG (Fab2) antibody (Chemicon International) at a 1:20 dilution for $20 \mathrm{~min}$. They were then mounted in Fluorescent mounting medium (DakoCytomation, Carpinteria, CA, USA), and pictures were taken under a fluorescence microscope (BX50F4; Olympus, Tokyo, Japan).

VIPR1-positive cells were counted under x200 magnification over three microscopic fields each in the lamina propria, submucosa, and muscular layer and expressed as the number of positive cells/one optical field.

Immunofluorescent double-staining. Immunofluorescent double-staining was performed using anti-CD3 (T-cell; DakoCytomation), anti-CD19 (B-cell; DakoCytomation), anti-CD68 (Macrophage; DakoCytomation), anti-IL-4 (Th2 cytokine; R\&D Systems), and anti-TNF- $\alpha$ (Th1 cytokine; DakoCytomation) antibodies with anti-VIPR1 (Chemicon) antibody. Sections were reacted with anti-CD3, anti-CD19, anti-CD68, anti-IL-4, and anti-TNF- $\alpha$ monoclonal antibodies at $4^{\circ} \mathrm{C}$ overnight, washed with PBS-T, and then reacted with rhodamine-conjugated goat anti-mouse IgG antibody (Chemicon) at a 1:20 dilution at an ambient temperature for $30 \mathrm{~min}$. Sections were washed with PBS-T and reacted with rabbit anti-VIPR 1 antibody at a 1:500 dilution at $4^{\circ} \mathrm{C}$ over- 

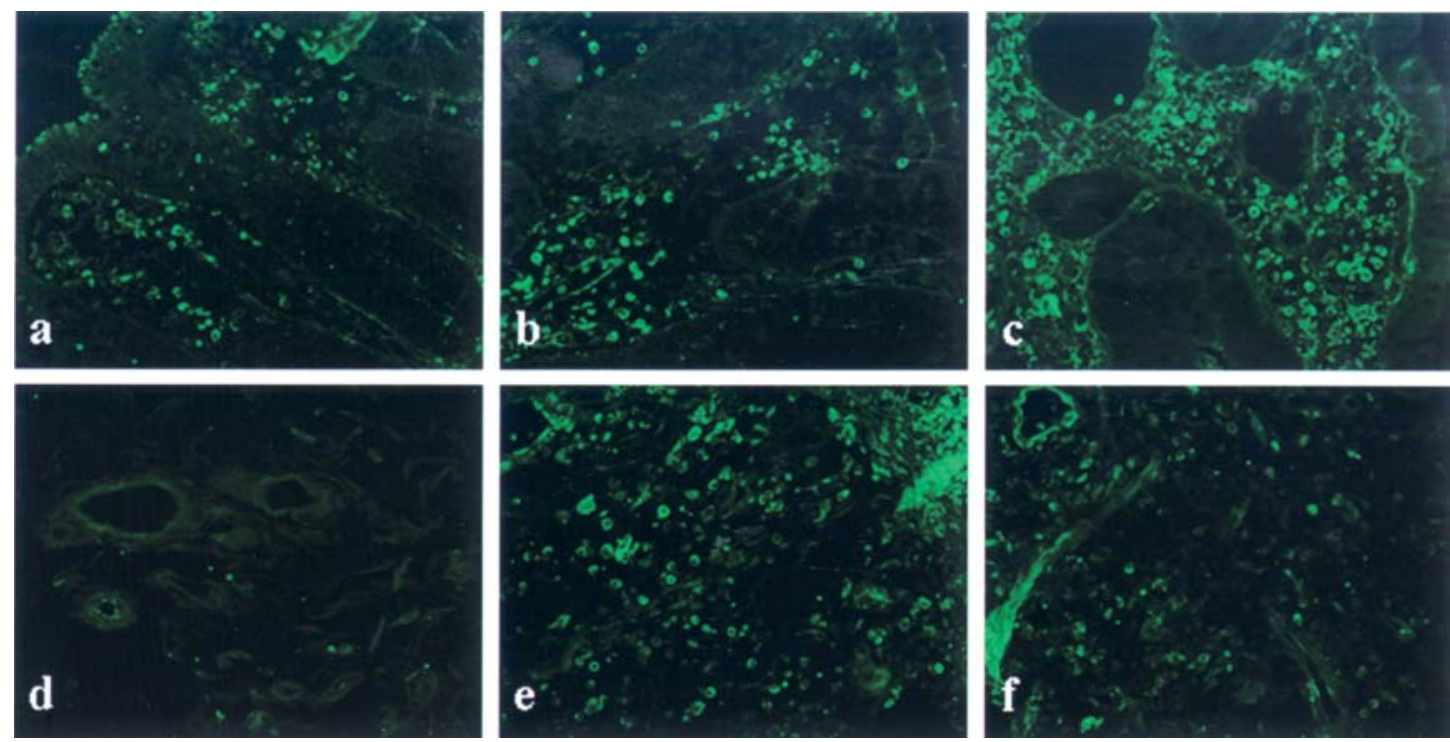

Figure 1. Immunohistochemical staining for VIPR1. VIPR1-positive cells were observed mainly in the lamina propria and submucosa. (a) Lamina propria in control, (b) lamina propria in UC, (c) lamina propria in CD, (d) submucosa in control, (e) submucosa in UC, and (f) submucosa in CD (Original magnification $\mathrm{x} 200)$.
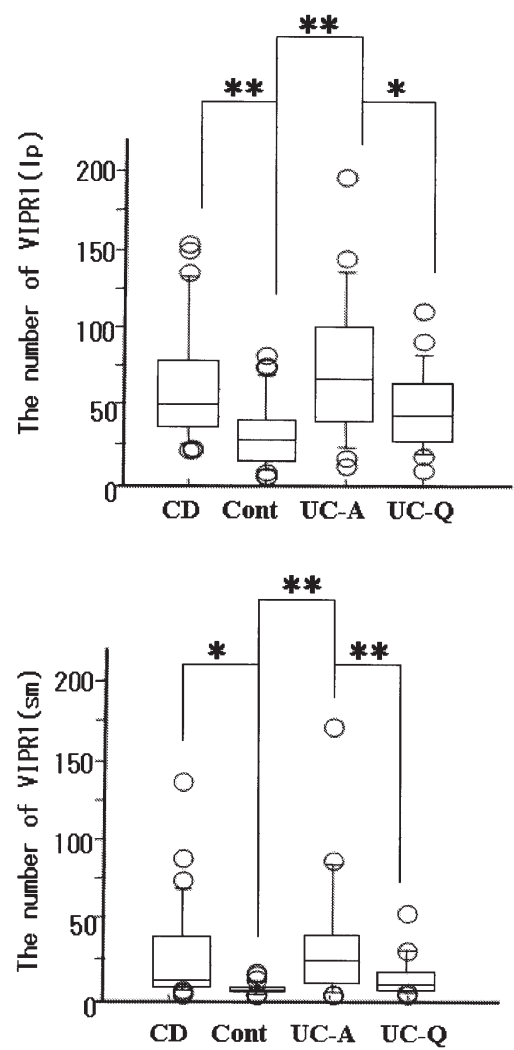

Figure 2. Quantification of VIPR1-positive cells in the human intestine. The number of VIPR1-positive cells was significantly higher in the lamina propria (lp, top diagram) of patients with active $\mathrm{UC}$ or $\mathrm{CD}$ than in the controls. The number of VIPR1-positive cells was significantly higher in the submucosa (sm, bottom diagram) of patients with active UC or CD than in the controls. UC-A, UC active; UC-Q, UC quiescent; and Cont, controls. ${ }^{*} \mathrm{p}<0.05,{ }^{* *} \mathrm{p}<0.001$.

night. After washing with PBS-T, sections were reacted with FITC-conjugated goat anti-rabbit IgG (Fab2) antibody (Chemicon) at a 1:20 dilution at an ambient temperature for
30 min. They were then mounted in Fluorescent mounting medium, and pictures were taken under a fluorescence microscope. VIPR1 single-positive cells were indicated by green, while CD3, CD19, or CD68 single-positive cells were red and double-positive cells were yellow.

VIPR1 expression was determined in CD3-, CD19- or CD68-positive cells in three microscopic fields each at x200 magnification in the lamina propria and submucosa, and expressed as percentages of CD3-, CD19-, and CD68-positive cells. The numbers of IL-4-, TNF- $\alpha$ - and VIPR1-positive cells were counted in the same section at $\mathrm{x} 200$ magnification in three microscopic fields in the lamina propria and submucosa, and the correlations between the numbers of VIPR1positive cells and of IL-4- and TNF- $\alpha$-positive cells were assessed.

Statistical analysis. Results were examined by one-way analysis of variance with Fisher's PLSD test and regression analysis with StatView software. Differences were considered significant when $\mathrm{p}$ values were $<0.05$.

This study was approved by Osaka City University's Ethics Committee, and informed consent was obtained from all patients and controls.

\section{Results}

Expression of VIPR1-positive cells. VIPR1-positive cells were observed mainly in the lamina propria and submucosa, and were rarely found in the muscular layer (Fig. 1). The number of VIPR1-positive cells was significantly higher in the lamina propria of patients with active $\mathrm{UC}$ or CD than in the controls (active UC vs control, $\mathrm{p}<0.0001$; CD vs control, $\mathrm{p}=0.0010$; and active UC vs quiescent UC, $\mathrm{p}=0.0108$ ). The number of VIPR1-positive cells was significantly higher in the submucosa of patients with active UC or CD than in the controls (active UC vs control, $\mathrm{p}<0.0001$; active UC vs quiescent UC, $\mathrm{p}=0.0051$; and $\mathrm{CD}$ vs control, $\mathrm{p}=0.0017$ ) (Fig. 2). 

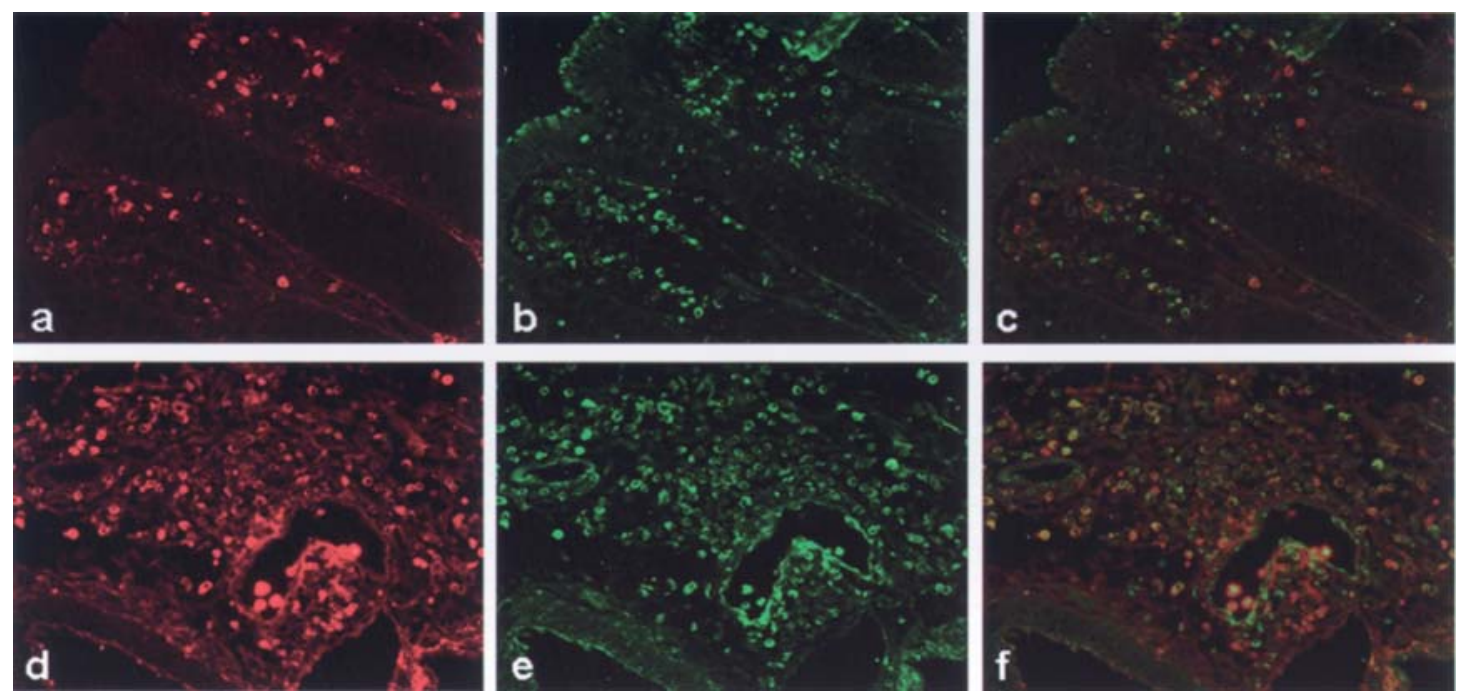

Figure 3. Immunohistochemical staining for CD3 and VIPR1. Double-immunostaining for CD3 and VIPR1 in control and UC lamina propria. (a) CD3positive cells in the control lamina propria, (b) VIPR1-positive cells in the same specimen, (c) merged imaging of both CD3- and VIPR1-positive cells in the same specimen, (d) CD3-positive cells in the UC lamina propria, (e) VIPR1-positive cells in the same specimen, and (f) merged image of both CD3- and VIPR1-positive cells in the same specimen. CD3-positive cells are observed in red, VIPR1-positive cells in green, and double-positive cells in yellow.
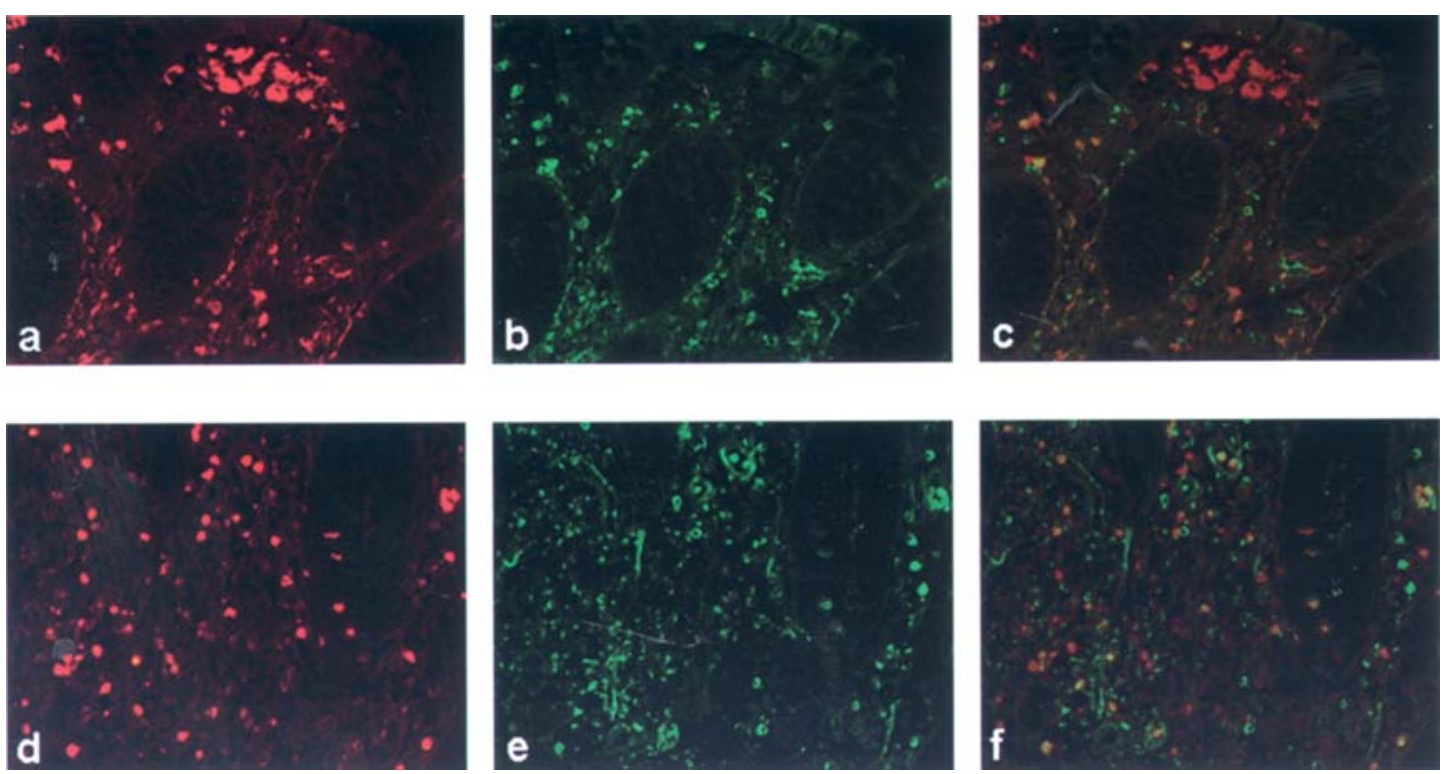

Figure 4. Immunohistochemical staining for CD68 and VIPR1. Double-immunostaining for CD68 and VIPR1 in control and UC lamina propria. (a) CD68positive cells in control lamina propria, (b) VIPR1-positive cells in the same specimen, (c) merged image of both CD68- and VIPR1-positive cells in the same specimen, (d) CD68-positive cells in UC lamina propria, (e) VIPR1-positive cells in the same specimen, and (f) merged image of both CD68- and VIPR1positive cells in the same specimen. CD68-positive cells are observed in red, VIPR1-positive cells in green, and double-positive cells in yellow.

Correlations between the number of VIPR1-positive cells and the clinical activity of patients with UC or CD. In patients with UC, there was no significant correlation between the number of VIPR1-positive cells and the clinical activity of $\mathrm{UC}$ (CAI, DAI). Likewise, in patients with CD, no correlation was found between the number of VIPR1-positive cells and the clinical activity of $\mathrm{CD}(\mathrm{CDAI})$.

Identification of VIPR1-positive cells. The proportions of VIPR1-positive cells were counted among CD3-, CD19-, and CD68-positive cells.
Lamina propria. In the lamina propria, the proportion of VIPR1-positive cells among CD3-positive cells was significantly higher in patients with active or quiescent UC than in the controls, and in patients with active UC than in those with $\mathrm{CD}$ (active UC vs control, $\mathrm{p}=0.0004$; quiescent UC vs control, $\mathrm{p}=0.0190$; and active UC vs $C D, p=0.0070$; Figs. 3 and 5). The proportion of VIPR1-positive cells among CD19-positive cells did not differ among the controls and patients with UC or CD. The proportion of VIPR1-positive cells among CD68-positive cells was significantly higher in patients with $\mathrm{UC}$ or $\mathrm{CD}$ than in the controls (active UC vs 

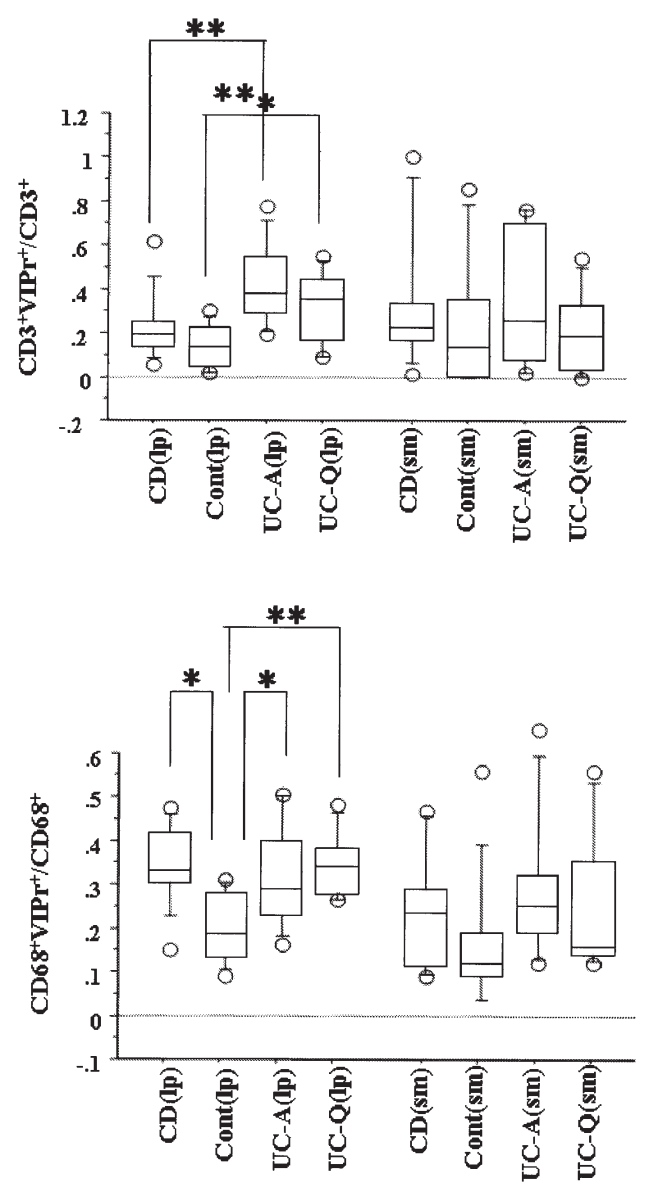

Figure 5. Proportions of VIPR1-positive cells among CD3 and CD68positive cells. The proportion of VIPR1-positive cells among CD3-positive cells (top diagram) was significantly higher in patients with active UC than in the controls and the CD patients, and in patients with quiescent UC than in those with $\mathrm{CD}$ in the lamina propria (lp). In the lamina propria, the proportion of VIPR1-positive cells among CD68-positive cells (bottom diagram) was significantly higher in patients with active or quiescent UC and patients with CD than in the controls. UC-A, UC active; UC-Q, UC quiescent; and Cont, controls. ${ }^{*} \mathrm{p}<0.05,{ }^{* *} \mathrm{p}<0.001$.

control, $\mathrm{p}=0.0126$; quiescent UC vs control, $\mathrm{p}=0.0044$; and CD vs control, p=0.0018; Figs. 4 and 5).

Submucosa. The proportions of VIPR1-positive cells among CD3-, CD19-, and CD68-positive cells did not differ significantly among the controls and patients with UC or CD.

Correlations between the number of VIPRI-positive cells and Th1 and Th2 cytokine expression. The numbers of VIPRpositive cells and IL-4-positive cells were significantly correlated in the lamina propria of patients with UC ( $\left.p=0.0214, \mathrm{R}^{2}=0.345\right)$. The numbers of VIPR-positive cells and TNF- $\alpha$-positive cells were significantly correlated in the lamina propria of patients with $\mathrm{CD}\left(\mathrm{p}=0.0194, \mathrm{R}^{2}=0.516\right)$ (Fig. 6).

On the other hand, in the submucosa, the number of VIPR1-positive cells was significantly correlated with the number of TNF- $\alpha$-positive (UC, $\mathrm{p}=0.0071, \mathrm{R}^{2}=0.439$; $\mathrm{CD}$, $\mathrm{p}=0.0020, \mathrm{R}^{2}=0.718$ ) and IL-4-positive (UC, $\mathrm{p}=0.0120$,
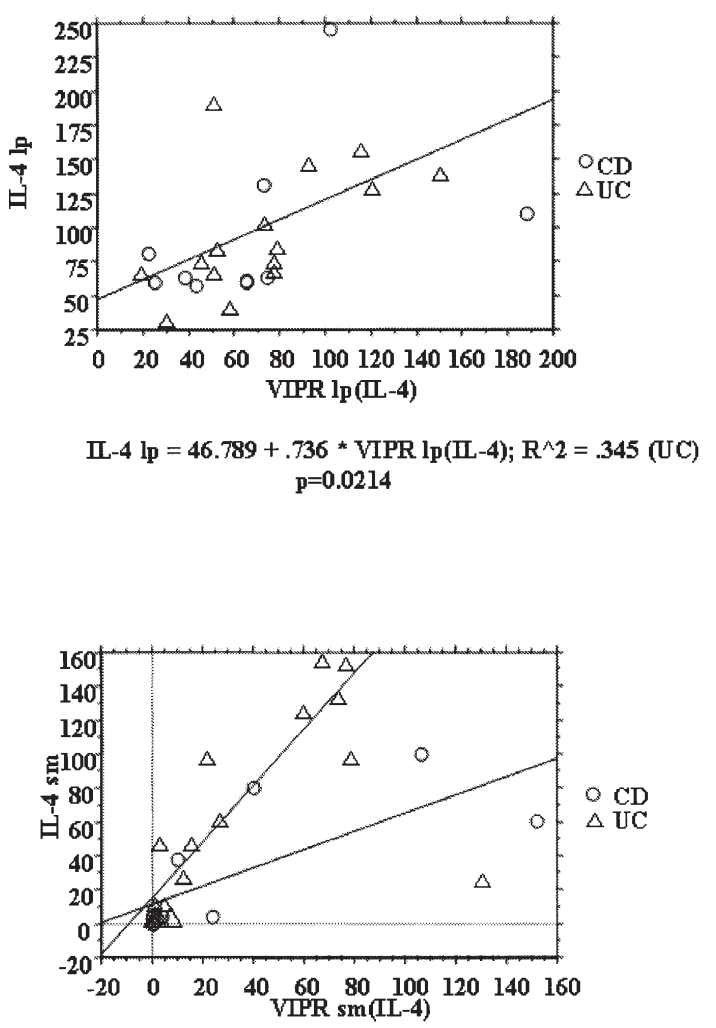

$$
\begin{aligned}
& \text { IL-4 sm }=11.345+.539 * \text { VIPR sm(IL-4); } \mathrm{R}^{\wedge} 2=.567(\mathrm{CD}) \\
& \mathrm{p}<0.0001 \\
& \text { IL-4 sm }=14.856+1.662 \text { * VIPR sm(IL-4); } \mathrm{R}^{\wedge} 2=.826 \text { (UC) } \\
& \mathrm{p}=0.0120
\end{aligned}
$$

Figure 6. Correlations between the numbers of VIPR1-positive cells and IL-4producing cells in the lamina propria (lp) and submucosa (sm). In the lp, the numbers of VIPR1-positive cells and IL-4-positive cells were significantly and positively correlated in the UC patients. In the sm, the numbers of VIPR1-positive cells and IL-4-positive cells were significantly and positively correlated in the UC and CD patients.

$\left.\mathrm{R}^{2}=0.826 ; \mathrm{CD}, \mathrm{p}<0.0001, \mathrm{R}^{2}=0.567\right)$ cells in patients with UC and those with CD (Fig. 7).

\section{Discussion}

In the present study, we found that VIPR 1 was mainly expressed on CD3-, CD19-, and CD68-positive cells in inflammatory mucosa. Expression of VIPR1 was significantly correlated with the numbers of CD3- and CD68-positive cells in the lamina propria of the patients with UC, and the number of CD68-positive cells in the lamina propria of those with CD. VIP is a pleiotropic peptide produced by neurons in different portions of the central and peripheral nervous systems (12-14) and by immunocytes, principally type 2 $\mathrm{T}$ cells (15). VIP inhibits in vitro and in vivo production of the proinflammatory cytokines TNF- $\alpha$, IL-2, IL-6, and IL-12, as well as nitric oxide, and stimulates the production of the anti-inflammatory cytokines IL-10 and IL-1Ra (16-20). VIP thus has strong anti-inflammatory activity and favors Th2 differentiation. VIP reduces the expression of the costimulatory molecules B7.1/B7.2 on activated macrophages and inhibits macrophage-induced activation of antigen- 


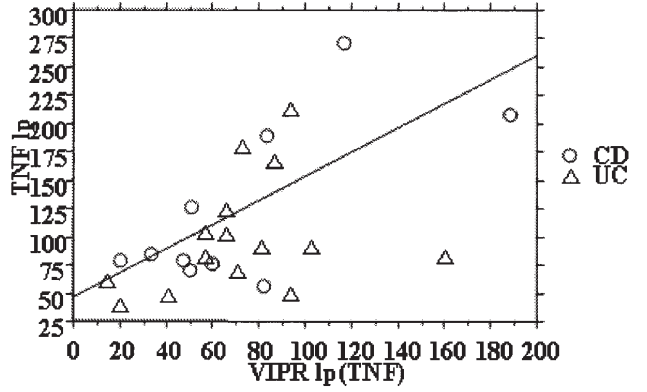

TNF lp $=45.879+1.073$ * VIPR $\operatorname{lp}(\mathrm{TNF}) ; \mathrm{R}^{\wedge} 2=.516(\mathrm{CD})$
$\mathrm{p}=0.0194$

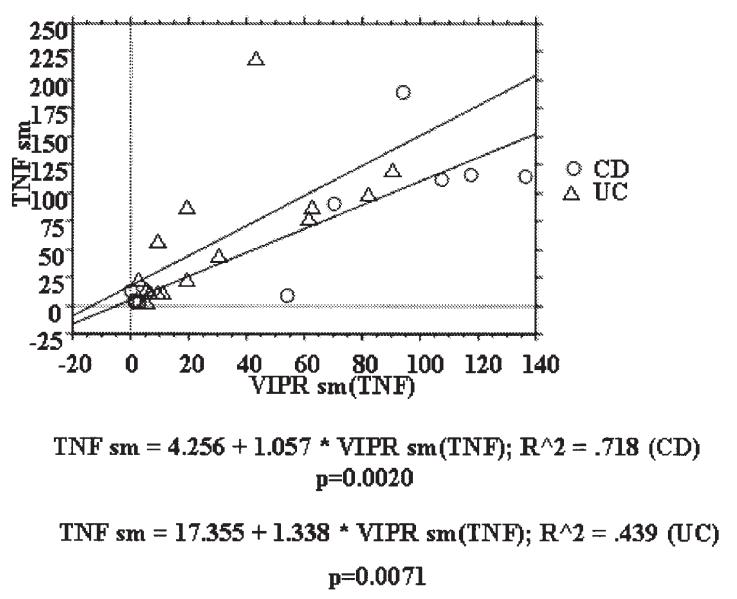

Figure 7. Correlations between the numbers of VIPR1-positive cells and TNF- $\alpha$-producing cells in the lamina propria (lp) and submucosa (sm). In the $1 \mathrm{p}$, the numbers of VIPR1-positive cells and TNF- $\alpha$-positive cells were significantly and positively correlated in the CD patients. In the sm, the numbers of VIPR1-positive cells and TNF- $\alpha$-positive cells were significantly and positively correlated in the UC and CD patients.

specific $\mathrm{T}$ cells, reduces IL-12 production by activated macrophages, and inhibits the subsequent differentiation of primed $\mathrm{T}$ cells into Th1 effectors (21). VIP receptors have been identified in human normal lymphocytes, NK cells, macrophages, dendritic cells, osteoclasts, and mast cells of various organs (21). The three VIP/PACAP receptors that have been cloned are the PAC1, VIPR1, and VIPR2 receptors, which bind VIP and PACAP with equal affinity, and the PAC1 receptor, which is PACAP selective. In the gastrointestinal tract, VIPR1 immunoreactivity is abundant in the epithelial cells and myenteric neurons of the human intestine (22). However, the present study demonstrated localization of VIPR1 in infiltrating inflammatory cells of the human lower intestine, while VIPR1 expression was minimal in epithelial cells. This discrepancy in the findings could be due to the use of different antibodies and methods of tissue preparation (paraffin-embedded tissue with heat-induced epitope retrieval vs PLP-fixed frozen sections) in the previous and present studies.

Todorovic et al (23) found higher serum and rectal concentrations of VIP in moderately and severely active UC than in mildly active UC and controls. Increased serum VIP originated from inflammatory cells of the lamina propria as well as the epithelial layer in addition to the lamina propria VIP fibers and submucosal ganglion cells in active UC. On the other hand, there have been conflicting reports of decreases in concentrations of VIP and the numbers of VIP neurons in inflamed intestine $(24,25)$.

Conflicting effects of VIP have been reported in models of experimental colitis. Abad et al (8) found that treatment with a VIP enema reduced the clinical and histopathologic severity of TNBS-induced colitis in a murine model of Crohn's disease. Treatment with VIP injection of TNBS mice reduced the expression of proinflammatory molecules such as the enzyme COX-2, the chemokines CX3CL1, CXCL12, CXCL13, CXCL14, CCR5, and CXCR2, and the cytokines IL-1ß, IL-12, IL-18, IL-10, interferon (IFN)- $\gamma$, and IL-4, and increased the expression of anti-inflammatory IL-10 and the Th2 cytokine IL-4 (10), showing that its beneficial effects are mediated through inhibition of the inflammatory/Th1 response (25). On the other hand, Newman et al (26) reported that continuous subcutaneous infusion of VIP by implanted mini-osmotic pumps and intraperitoneal injection of VIP in TNBS mice failed to improve macroscopic and histological inflammation, and did not alter plasma cytokine levels. These two studies suggest that topical administration of VIP may be essential in the treatment of IBD.

In the present study, VIPR1 was found to be widely expressed in infiltrating inflammatory cells, especially CD68positive cells in the lamina propria of both active UC and CD mucosa. The most significant finding of the present study was the significantly greater infiltration of VIPR1-positive T cells in the lamina propria of the UC intestine. This differential VIPR 1 expression in T cells may contribute to the differences in alteration of the Th1/Th2 balance in the pathogeneses of $\mathrm{UC}$ and $\mathrm{CD}$.

The alteration of the Th1/Th2 cytokine balance has been considered the most important mechanism of pathogenesis in patients with IBD, and Th1 dominance in CD and Th2 dominance in UC has been recognized $(27,28)$. Expression of VIPR1 on intestinal macrophages induces a Th2-dominant cytokine profile in reaction to the VIP signal in the IBD intestine. In our study, the number of VIPR-positive cells was significantly correlated with that of IL-4-positive cells in the intestinal mucosa of patients with $\mathrm{UC}$, reflecting the Th2 response in UC. VIP may be involved in the production of Th2 cytokines through its receptors, expressed on infiltrating cells. On the other hand, the correlation found between numbers of VIPR1-positive cells and TNF- $\alpha$-positive cells in CD mucosa may represent an association with Th1 skewing. In the CD intestine, the number of VIPR1-positive cells was differentially correlated with Th1 cytokine levels in the lamina propria and Th1/2 cytokine levels in the submucosa. Concerning the Th1-dominant response in the pathogenesis of CD, increased VIPR1 T-cells and macrophages may be a counter-reaction to increased $\mathrm{Th} 1$ response in the $\mathrm{CD}$ intestine. The role of VIPR 1 activation in IBD requires further elucidation.

VIPR 1 is differentially expressed in inflammatory cells in $\mathrm{UC}$ and CD in terms of the Th1/Th2 balance. Although the reason for this is not clearly known, VIPR 1 appears to contribute to intestinal inflammation through both T-cell and 
macrophage activation in UC, and macrophage activation in CD. VIP administration may be useful as a new treatment for Crohn's disease due to its strong anti-inflammatory effect mediated via the shifting of Th1 to Th2 responses through receptors on macrophages.

In conclusion, our findings suggest that VIPR 1 may play an important role in immune responses in IBD.

\section{References}

1. Baldassano RN, Schreiber S, Johnston RB Jr, Fu RD, Muraki T and MacDermott RP: Crohn's disease monocytes are primed for accentuated release of toxic oxygen metabolites. Gastroenterology 105: 60-66, 1993

2. Monteleone I, Vavassori P, Biancone L, Monteleone G and Pallone F: Immunoregulation in the gut: success and failures in human disease. Gut 50 (suppl 3): 60-64, 2002.

3. Klein TW, Newton C and Friedman H: Cannabinoid receptors and immunity. Immunol Today 19: 373-381, 1998.

4. Bijlsma JWJ, Cutolo M, Masi AT and Chicanza IC: The neuroendocrine immune basis of rheumatic disease. Immunol Today 20: 298-301, 1999.

5. Gomariz RP, Martinez C, Abad C, Leceta J and Delgado M: Immunology of VIP: a review and therapeutical perspectives. Curr Pharm Des 7: 89-111, 2001.

6. Kimura M, Masuda T, Hiwatashi N, Toyota T and Nagura H: Change in neuropeptide-nerves in human colonic mucosa with inflammatory bowel disease. Pathol Int 44: 624-634, 1994.

7. Niessner M and Volk BA: Altered Th1/Th2 cytokine profiles in the intestinal mucosa of patients with inflammatory bowel disease as assessed by quantitative reversed transcribed polymerase chain reaction (RT-PCR). Clin Exp Immunol 101: 428-435, 1995.

8. Abad C, Martinez C, Juarranz MG, Arranz A, Leceta J, Delgado M and Gomariz RP: Therapeutic effects of vasoactive intestinal peptide in the trinitrobenzene sulfonic acid mouse model of Crohn's disease. Gastroenterology 124: 2003.

9. Satsangi J, Silvergerg MS, Vermeire S and Colombel J-F: The Montreal classification of inflammatory bowel disease: controversies, consensus, and implication. Gut 55: 749-753, 2006.

10. Truelove SC and Witts LI: Cortisone in ulcerative colitis. BMJ 2: 1041-1048, 1955.

11. Best WR, Becktel JM, Singleton JW, et al: Development of a Crohn's disease activity index. National Cooperative Crohn's Disease Study. Gastroenterology 70: 439-444, 1976.

12. Fuxe K, Hokfelt T, Said SI and Mutt V: Vasoactive intestinal polypeptide and the nervous system; immunohistochemical evidence of localization in central and peripheral neurons, particularly intracortical neurons of the cerebral cortex. Neurosci Lett 5: 241-246, 1977.

13. Covineau A, Rouyer-Fessard C, Darmoul D, Maoret JI, Carrero I, Ogier-Denis E and Laburthe M: Human intestinal VIP receptor: cloning and functional expression of two cDNA encoding proteins with different $\mathrm{N}$-terminal domains. Biochem Biophys Res Commun 200: 769-776, 1994.
14. Ishihara T, Shigemoto R, Mori K, Takahashi K and Nagata S: Functional expression and tissue distribution of a novel receptor for vasoactive intestinal peptide. Neuron 8: 811-819, 1992.

15. Delgado $M$ and Ganea D: Is vasoactive intestinal peptide a type 2 cytokine? J Immunol 166: 2907-2912, 2001.

16. Dewit D, Gourlet P, Amraoui Z, Vertongen P, Willems F, Robberetch $\mathrm{P}$ and Goldman M: The vasoactive intestinal peptide analogue RO25-1553 inhibits the production of TNF and IL-12 by LPS-activated monocytes. Immunol Lett 60 : 57-60, 1998.

17. Martinez C, Delgado M, Pozo D, Leceta J, Calvo JR, Ganea D and Gomariz RP: Vasoactive intestinal peptide and pituitary adenylate cyclase-activating polypeptide modulate endotoxininduced IL-6 production by murine peritoneal macrophages. J Leukocyte Biol 63: 591-601, 1998

18. Xin Z and Sriram S: Vasoactive intestinal peptide inhibits IL-12 and nitric oxide production in murine macrophages. J Neuroimmunol 89: 206-212, 1998.

19. Delgado M: Vasoactive intestinal peptide and pituitary adenylate cyclase-activating polypeptide inhibit CBP-NFkappaB interaction in activated microglia. Biochem Biophys Res Commun 297: 1181-1185, 2002.

20. Ganea D: Regulatory effects of VIP on cytokine production in central and peripheral lymphoid organs. Adv Neuroimmunol 6: 61-74, 1996.

21. Delgado M, Pozo D and Ganea D: The significance of vasoactive intestinal peptide in immunomodulation. Pharmacol Rev 56: 249-290, 2004.

22. Schulz S, Rocken C, Mawrin C, Weise W, Hollt V and Schulz S: Immunocytochemical identification of VPAC1, VPAC2, and PAC1 receptor in normal and neoplastic human tissues with subtype-specific antibodies. Clin Cancer Res 10: 8235-8242, 2004.

23. Todorovic V, Janic B, Koko V, Micev M, Nikolic JA, Ratkovic M, Leposavic G, Jankovic T, Knezevic-Usaj S and Milicevic Z: Colonic vasoactive intestinal polypeptide (VIP) in ulcerative colitis - a radioimmunoassay and immunohistochemical study. Hepatogastroenterology 43: 483-488, 1996.

24. Koch TR, Carney JA and Go VL: Distribution and quantitation of gut neuropeptides in normal intestine and inflammatory bowel disease. Dig Dis Sci 4: 369-376, 1987.

25. Kubota Y, Petras RE and Ottaway CA: Colonic vasoactive intestinal peptide nerves in inflammatory bowel disease. Gastroenterology 102: 1242-1251, 1992.

26. Newman R, Cuan N, Hampartzoumian T, Connor SJ, Lloyd AR and Grimm MC: Vasoactive intestinal peptide impairs leucocyte migration but fails to modify experimental murine colitis. Clin Exp Immunol 139: 411-420, 2005.

27. Nielson OH, Koppen T, Rudiger N, Horn T, Eriksen J and Kirman I: Involvement of interleukin-4 and -10 in inflammatory bowel disease. Dig Dis Sci 9: 1786-1792, 1998.

28. Inoue S, Matsumoto T, Iida M, et al: Characterization of cytokine expression in the rectal mucosa of ulcerative colitis: correlation with disease activity. Am J Gastroenterol 94: 2441-2446, 1999. 